\title{
The Impact of Task Complexity on Iranian EFL Learners' Listening Comprehension across Anxiety and Proficiency Levels
}

\author{
Mehdi Sadeghi Ghahdarijani \\ English Department, University of Kashan, Kashan, Iran \\ Email: m.sadeghi58@yahoo.com
}

\begin{abstract}
This study investigates the impact of task complexity on Iranian EFL learners' listening comprehension across anxiety and proficiency levels. To this end, two intact EFL classes including 54 Iranian EFL learners at an English department $(F=39, M=15)$ were selected. Test-takers' anxiety was assessed by filling an anxiety questionnaire (Abolghasemi et al, 1997) and their proficiency was assessed by a proficiency test. Three task dimensions, namely planning time, perspective, and prior knowledge, each under two +/complex \& -/simple conditions (i.e., task manipulated for complexity and simple task) were used in testtakers' listening performance. The participants' listening performance was analyzed using descriptive statistics, one-way ANOVA and post hoc Tukey's HSD test. Results showed that test-takers' listening performance was a little better under simple conditions than complex ones for all task dimensions. Another is that except planning time $(p=.012)$, between low and average proficiency levels under simple condition, no significant differences were found in the listening task performances among the three proficiency levels. Finally, the results didn't show any significant difference among performance of three different anxiety levels under both simple and complex conditions. In short, this study didn't show any considerable effect of proficiency and anxiety on task complexity.
\end{abstract}

Index Terms - task complexity, task difficulty, task condition, perception of task difficulty, students' anxiety, students' proficiency

\section{INTRODUCTION}

A task is seen as a differentiated goal-oriented process with a number of steps which draws on a series of cognitive and communicative procedures and that has a defined outcome. Additionally, tasks are sequenceable and can be subject to pedagogical intervention. Apart from its pedagogic dimension, tasks can be manipulated for empirical enquiry. Michael Long (1985, p. 19) defined task in its everyday meaning as follows: "A piece of work undertaken for oneself or for others, freely or for some reward. Thus, examples of task include painting a fence, making an airline reservation, etc."

In this sense the concept of task is used when discussing human skills performance models. Crookes (1986) suggested that in Long's definition, the category task has a psychological reality. According to Long (1985), Much, if not most, of human activity, whether in employment or in the classroom can be seen a series of tasks - some having a communicative aspect, others not.

Gilabert (2004) elaborated on the tasks in Long's example; a simple task in which language is not involved would be painting a fence and an example of a complex task is one in which language is required: Interviewing a source in the domain of journalism (decision making process, contacting the source, documenting the interview, etc.).

As far as pedagogic tasks are concerned, following previous task definitions, Skehan (1998, p. 95) identified a series of defining traits most researchers would agree on when conceptualizing a task:

A task is an activity in which meaning is primary; there is some kind of communication problem to solve; there is some sort of relationship to comparable real-world activities; task completion has some priority; the assessment of the task is in terms of outcome.

According to Bygate (2001), however, tasks are susceptible to pedagogic intervention; tasks can be influenced by learner choice and can be potentially reinterpreted by learners. As Bygate (2001) pointed out, tasks may have a static, controllable nature if used for research, and they may include more dynamic and extended qualities if they are used for teaching purposes. That is why they pointed out that it may be necessary to clarify the definition of task under different circumstances, who to determine the tasks` goals and how to sequence tasks.

In a study for exploring task difficulty in ESL listening assessment Brindley \& Slatyer (2002) adopted the definition of 'task' proposed by the Association of Language Testers in Europe (2001) defined as following:

A combination of rubric, item, and response. For example, a reading text with several multiple-choice items, all of which can be responded to by referring to a single rubric.

As Davies et al. (1999) in their study pointed out, the terms 'item' and 'task' tend to overlap: 
Item is smaller and less complex, while a task is larger and more complex. A test would typically include either a large number of relatively short items or a small number of relatively complex tasks.

As we can see above, a task for assessing the listening competency described above would thus consist of the input text that learners hear along with the accompanying set of items and instructions.

The three main approaches to the characterization of tasks are interactional approaches, information-processing approaches, and test-method approaches. One tradition, stemming from the work of interactionists (e.g., Pica, 1994; Pica, Kanagy, \& Falodun, 1993), has attempted to determine the interactional characteristics of tasks and their impact on negotiation in dyadic communication. A second tradition, the information processing approach, perhaps best known in the work of Skehan and Robinson (1996, 1998; 1995), has examined the impact on performance of the cognitive characteristics of tasks, and links have been explicitly made with predictions of task difficulty. A third tradition, in which test task characteristics are defined as test methods (for example in work by Bachman\& Palmer, 1996), has suggested that the impact of task differences can best be understood as a question of test-method effects. Of course, our study has focused on second tradition, information processing approach, to examine the impact of cognitive characteristic of tasks on task difficulty in listening.

The concept of task complexity was emerged from the need to establish criteria for sequencing tasks in a syllabus from easy/simple to difficult/complex in a way that will foster interlanguage development. Rather than looking at the linguistic features of language activities, syllabi that used tasks as their units have focused on task design in order to find out how tasks impose cognitive demands on learners.

One of the first attempts at sequencing tasks from simple to complex was done by Brown et al. (1984). They distinguished among three different types of tasks which they presented as ranging from easy to difficult. Table 2.2 shows an example of tasks arranged in ascending difficulty as suggested by Brown et al. (1984):

TABLE 2.2

TASKS OF ASCENDING DIFFICULTY (BROWN ET AL., 1984)

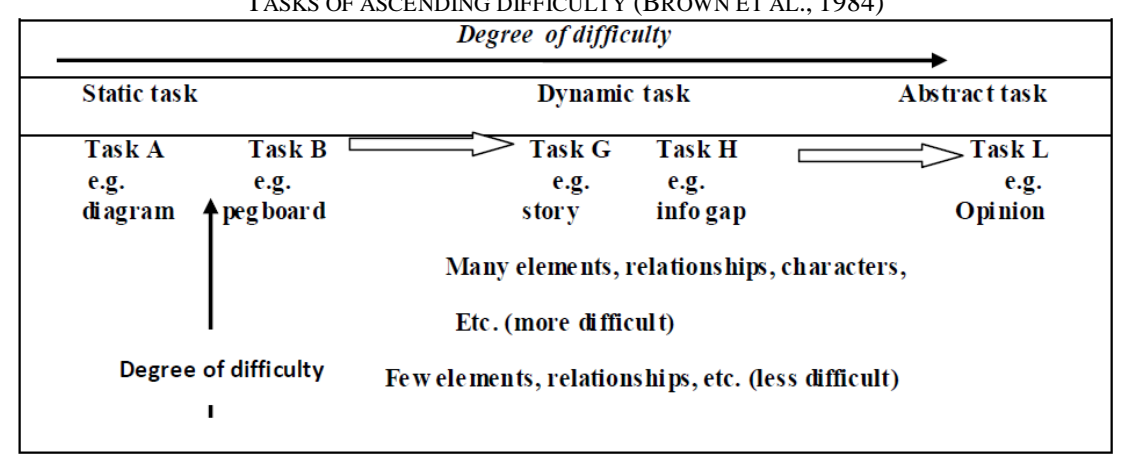

Another suggestion for sequencing tasks in a syllabus comes from the "Bangalore Communicative Teaching Project" in India, in which Prahbu (1987, p. 47) suggested the grading of tasks according to a number of criteria which he described as "rough measures of cognitive complexity." Figure 2.3 shows a brief view of these criteria.

FIGURE 2.3

CRITERIA SUGGESTED BY PRABHU (1987) TO DETERMINE TASK COMPLEXITY.

\begin{tabular}{|lll|}
\hline- & Degree of difficulty & + \\
\hline Few elements & AMOUNT OF INFORMATION & Many elements \\
\hline Few steps & AMOUNT OF REASONING & Many steps \\
\hline Precise terms not needed & DEGREE OF PRECISION & Precise terms needed \\
\hline Unfamiliar & DEGREE OF FAMILIARITY & Familiar \\
\hline Objects and actions & DEGREE OF ABSTRACTNESS & Concepts \\
\hline
\end{tabular}

Robinson (2001a) shifted the focus from grading and sequencing to the cognitive processes involved in task production. Robinson (2001a, p. 28) said that:

Task complexity is the result of the attentional, memory, reasoning, and other information processing demands imposed by the structure of the task on the language learner.

Robinson proposed three-dimensional model (see Table 2.2) that distinguishes between three different types of factors: 
TABLE 2.2

ROBINSON'S MODEL OF TASK COMPLEXITY, BASED ON ROBINSON (2001 A; 2001B; 2003A)

\begin{tabular}{|l|l|l|}
\hline Cognitive factors & Interactive factors & Difficulty factors \\
\hline Task complexity & Task conditions & Task difficulty \\
a) Resource directing & a) participation variables & a) affective variables \\
e.g.,+/- few elements & e.g., one way/two way & e.g., motivation \\
+/- Here-and-Now & convergent/divergent & anxiety \\
+/- No reasoning demand & Open/closed & confidence \\
b) Resource dispersing & b) participant variables & b) ability variables \\
e.g., +/- planning & e.g., gender & e.g., aptitude \\
+/- Single task & Familiarity & proficiency \\
+/- Prior knowledge & Power/solidarity & intelligence \\
\hline
\end{tabular}

By task difficulty, Robinson (2001a; 2001b; 2003a) meant what learners bring to the task, and suggested that differentials in ability variables (e.g. working memory capacity) affect learners' perception of the task with consequences for performance and learning (e.g. a learner with low proficiency may find a task so hard that he or she cannot produce or learn anything from it). To summarize, task difficulty is determined by learner variables (affect, e.g., confidence, and physical abilities, e.g., eyesight).

Skehan's conception of task-based learning comes from a communicative approach to language teaching (based on Brumfit, 1984; Widdowson, 1972). Skehan (1998; Skehan \& Foster, 2001) suggested a three-way distinction of difficulty, to which learner factors can also be added (2.3).

TABLE 2.3

SKEHAN'S (1998) MODEL OF TASK DIFFICULTY.

\begin{tabular}{|l|l|l|l|}
\hline Code complexity & \multicolumn{2}{c|}{ Cognitive complexity } & Tearner factors \\
\hline Linguistic complexity & Cognitive familiarity & Scale pressure & Learner's intelligence \\
And variety & Familiarity of topic & Number of participants & Breadth of imagination \\
Vocabulary load and Variety & Familiarity of discourse & Length of text used & Podality \\
& Genre & Stake & Opportunity for control \\
& Familiarity of task & Cognitive processing & \\
& Information organization & & \\
& Amount of computation & & \\
& Clarity of information & & \\
& Sufficiency of information & & \\
\hline
\end{tabular}

The difficulty may be traced to the instruments chosen to measure anxiety in some of the studies and also multidimensional view of anxiety. As an example Endler's (1980) proposes that to study anxiety is to study the interaction of the person in the situation producing that anxiety. Some situations arouse anxiety while others do not, so both the individual and the context must be taken into consideration. Instruments such as the Taylor (1953) Manifest Anxiety scale or Spielberger's (1983) State-Trait Anxiety Inventory attempt to define a personality trait of anxiety applicable across several situations, but this may not be the best way to measure anxiety in a language Learning context.

Gardner and Macintyre (1993) recognized foreign language anxiety as an affective factor in foreign language learning and normally discussed alongside other individual learner differences that this area is still considered to be a relatively new and developing within foreign language research. Different researchers have approached FLA from different aspects. From a broader perspective, anxiety itself was defined by psychologists like Spielberger (1983, p.55) as "the subjective feeling of tension, apprehension, nervousness, and worry associated with an arousal of the autonomic nervous system". Literature usually differentiates between three types of anxiety:

- Trait anxiety - which is a personality trait (Eysenck, 1979)

- State anxiety - which is apprehension experienced at a particular moment in time

- situational anxiety - which is anxiety experienced in a well-defined situation (MacIntyre \& Gardner, 1991a)

According to Horwitz, Horwitz and Cope (1991), possible causes of FLCA are communication apprehension (The inability either to express oneself or comprehend another person), test anxiety (apprehension over academic evaluation), and fear of negative evaluation (negative social evaluation or impression). According to Macintyre and Gardner (1989), these three components reviewed by Horwitz and Cope (1991) show to have a deleterious effect on second-language acquisition.

In study by Kleinmann (1977), he considers two types of anxiety, facilitating and debilitating. Facilitating anxiety is considered to be an asset to performance and showed the predicted positive correlations with Arabic students' willingness to attempt difficult linguistic structures in English. Debilitating anxiety, which is the more common interpretation of anxiety, is considered to be detrimental to performance, but did not show the expected negative correlations with performance. The concept of second-Language anxiety has also been investigated in the context of attitudes and motivation and their relationship to proficiency. Because the primary focus is on attitudes and motivation, detailed information is not always given about the relationship of anxiety to proficiency.

Macintyre and Gardner (1989) claim that while the instruments used to measure language anxiety should be specific to the language area, theoretical links to the more general anxiety literature can be strengthened. For example, Tobias (1986) proposes a model of the effects of anxiety on Learning from instruction. He suggested that anxious persons tend 
to engage in self-directed, derogatory cognition rather than focusing on the task itself. These task-irrelevant thoughts compete with task-relevant ones for limited cognitive resources. Non-anxious individuals tend not to engage in such self-preoccupations, giving them an advantage when the task at hand is taxing. Tobias's theory helped to explain the often cited finding of an interaction between anxiety, task difficulty, and ability (e.g. Sarason, 1986 Spielberger, 1983).

According to Tobias (1986), interference may occur at three levels: input, processing and output. At input, anxiety may cause attention deficits and poor initial processing of information. In short, not as much information is registered. For example, people with higher anxiety seem easily distracted from the task because time is divided between the processing of emotion-related and task-related cognition. If the task is relatively simple, anxiety may have little effect on processing. The more difficult the task becomes, relative to ability, the greater the effect of anxiety on processing. Interference with the rehearsal of new information would be an example of this type of effect. At output, anxiety may interfere with the retrieval of previously learned information. The experience of 'freezing on a test can be attributed to the influence of anxiety at the time of retrieval.

Subsequently, one needs to identify measures (e.g., of learner production and comprehension on task) that will capture the effects of the proposed complexity differential. The degree of precision in language use that a task requires, as well as the propositional load and amount of information storage and retrieval that it imposes on the interlocutors will be factors to consider (Givon, 1989; Sridhar, 1988). Long (1989) stated that tasks requiring accurate or precise use of language, and requiring the expression of multiple propositions drawn from memory, are more likely to "stretch" the interlanguage resources of second language users than are tasks not requiring them, and so will lead to greater communicative resource expansion.

As Robinson (2001) stated, in contrast to affective variables, ability variables such as aptitude, intelligence, and cognitive style can often be diagnosed ahead of syllabus implementation but here again there is as yet no clear research evidence of stable and predictable interactions between them and L2 task complexity and performance. A fourth ability variable, proficiency, is often the basis of placement into different levels of a programme. Therefore proficiency is not likely to be a factor that is available for on-line methodological manipulation. However, proficiency level will, of course, influence decisions about task content and the level of language input to a task. According to Slatyer et al. (2000), one possible explanation which would need to be explored empirically, is that learner factors such as anxiety, confidence, and motivation - produce different levels of stress and engagement during task performance and that, in result, these interact in complex ways with the characteristics of the tasks themselves. Iwashita and Elder (1997) in a study on expert feedback found that language proficiency was a more powerful factor than any other background variable in determining their participants' reactions to the listening component of a Japanese proficiency test for teachers.

In line with this research tradition and to make up for the lack of systematic research on this issue in Iran, the present study was designed to focus on effect of proficiency and anxiety on task complexity in context of listening performance of Iranian university EFL learners and to determine possible quantitative differences.

\section{METHODOLOGY}

This study aimed to compare the listening performance of EFL learners on different simple and complex tasks and to examine the effect of anxiety and proficiency on this complexity. The study used a mainly quantitative framework to answer the following research questions.

1. Is there any difference between test-takers' task performance with different proficiency levels under simple and complex performance conditions in listening comprehension context?

2. Is there any difference between test-takers' anxiety and their task performance under different performance conditions in listening comprehension context?

\section{A. Participants}

A total of 54 students enrolled in an EFL conversation class $(M=15 \mathrm{~F}=39)$ participated in the present study and provided the English listening samples needed for the analyses. This quasi-experimental design for data collection was selected to allow for the control of performance conditions. The participants, aged from 18 to 24 , were second-year intermediate learners based on their placement records and institutional proficiency records. They were majoring in English literature at the University of Kashan, Iran. They had passed two introductory conversation courses, and at the time of data collection, they were on a third course in the English department called "Advanced conversation" which does not of course teach what its name implies. The main focus of the "Advanced conversation" course is to teach the participants the key concepts of communication strategies including listening and speaking strategies for opening, maintaining and closing conversations.

\section{B. Instruments}

An institutional version of TOEFL listening comprehension proficiency test was used to control any differences between test takers' proficiency levels. Four listening comprehension texts or tasks (totally 24 items form TOEFL, each 8 multiple choice listening task for a dimension) were selected from a version of TOEFL test (Test Preparation Kit) for three specified dimensions of task complexity described by Skehan (1996; 1998) cited in Mc Namara et al. (2001) and 
Robinson (2001a) models of task complexity mentioned in following table. Two different conditions for each dimension resulting six task conditions as shown below.

TABLE 1.

DIFFERENT TASK CONDITIONS USED IN THIS STUDY

\begin{tabular}{|l|l|l|}
\hline Dimensions of task complexity & Condition one ( $)$ & Condition two (+) \\
\hline $\begin{array}{l}\text { planning time, } \\
\text { Perspective, Prior knowledge }\end{array}$ & Simple & Manipulated for complexity \\
\hline
\end{tabular}

The rationale for varying the comprehension conditions within each dimension was that this would either make the tasks easier (i.e., less cognitively demanding) or more difficult (i.e., more cognitively demanding) for students. There were two comprehension conditions labeled plus (+/complex) or minus (-/simple) according to the predicted difficulty for students (see Table 3.1).

TABLE 2.

TASK COMPLEXITY CONDITIONS ADAPTED FROM SKEHAN (1996; 1998) CITED IN MC NAMARA ET AL. (2001) AND ROBINSON (2001A) MODELS OF TASK COMPLEXITY.

\begin{tabular}{|l|l|l|}
\hline Dimensions & \multicolumn{1}{l|}{$\begin{array}{l}\text { Predicted difficulty (according to assumed degree of cognitive demand) } \\
\text { Complex/+ }\end{array}$} & $\begin{array}{l}\text { Having time to look at the listening items before } \\
\text { listening to the tasks }\end{array}$ \\
\hline Planning time & $\begin{array}{l}\text { Not having time to look at the listening items } \\
\text { before listening to the tasks }\end{array}$ & $\begin{array}{l}\text { Answering the task items after listening to task } \\
\text { with first person point of view }\end{array}$ \\
\hline Perspective & $\begin{array}{l}\text { Answering the task items after listening to task } \\
\text { with third person point of view }\end{array}$ & $\begin{array}{l}\text { Reading related written prior knowledge before } \\
\text { listening and answering the task }\end{array}$ \\
\hline Prior knowledge & $\begin{array}{l}\text { Listening to the task and answering the task items } \\
\text { without prior knowledge }\end{array}$ \\
\hline
\end{tabular}

A questionnaire on the students' trait anxiety was completed (A 25-item questionnaire with a four-point Likert scale; never, seldom, sometimes and always; prepared and validated by Abolghasemi et al, 1997). Based on students' score of anxiety, we divided them into three high, low and average groups and compared their performances.

\section{Procedures}

All participants were assigned to two groups. The data were collected in language laboratory of the University of Kashan. Data collection was done at two sessions. Since our complex tasks were the same as simple ones with some manipulations under complex conditions, we did two measures to decrease the test effects. First, we placed a four-week interval between the two sessions. Second, to reduce the test effect, counterbalancing of simple and complex tasks was done. In order to counterbalance such effects, the following measures shown in the following table were taken:

TABLE 3.

MANNER OF ADMINISTRATION BASED ON COUNTERBALANCING.

\begin{tabular}{|l|l|l|l|l|}
\hline \multirow{2}{*}{ sessions } & Dimensions: & Planning time & Perspective & \multirow{2}{*}{ Prior knowledge } \\
\cline { 2 - 5 } & Groups & & & Complex \\
\hline \multirow{3}{*}{ First session } & Group $\boldsymbol{A}$ & Simple & Complex & Simple \\
\cline { 2 - 5 } Second session & Group $\boldsymbol{B}$ & Complex & Simple & Simple \\
\cline { 2 - 5 } & Group $\boldsymbol{A}$ & Complex & Simple & Complex \\
\cline { 2 - 5 } & Group $B$ & Simple & Complex & . \\
\hline
\end{tabular}

Note: Complex task is the same task manipulated for complexity.

At the first session, test-takers were briefed about how to answer the anxiety questionnaire and listening tasks. Then, they were asked to complete an anxiety questionnaire (Abolghasemi et al, 1997) for ten minutes. After listening to a sample listening task, test-takers in two groups listened and answered to the tasks for three task dimensions respectively as it was explained in Table 3.3. To recognize and control listening comprehension tasks, one point was rewarded to each correct answer and no point for incorrect answers.

\section{Data Analysis}

Different kinds of statistical analyses are used in this thesis: Regarding two research hypotheses, participants' listening performance scores for low, average and high levels of anxiety and proficiency under simple and complex task conditions were analyzed using descriptive statistics of mean and standard deviation. To determine the significant differences between three different levels of students' proficiency and anxiety under simple and complex conditions, One-Way ANOVA were also applied. A follow-up post hoc Tukey's LSD (limited significant difference) test was conducted to examine the mean differences among the three levels of proficiency and anxiety for each task. A $p$ value of $<.05$ was used as the criterion of statistical significance for t-test ANOVAs, and pos hoc tests. A Microsoft Excel spreadsheet was used to enter data and to design graphs. All statistical analyses were carried out using statistical package SPSS 15.00 for Windows.

\section{RESUltS}


H1: There is no difference between test-takers' task comprehension with different proficiency levels under simple and complex conditions

This section explores the difference among three levels of proficiency for each of three task dimensions under two conditions (simple and complex).

To this end, students' listening performance for low, average and high levels was identified, and then the mean scores and standard deviation of students, as summarized in table 1, under + complex/- simple conditions were compared.

TABLE 1.

DESCRIPTIVE StATISTICS FOR STUDENTS’ LiSTENING COMPREHENSION SCORE FOR THREE LEVEL OF PROFICIENCY UNDER +/- CONDITIONS: MEAN AND STANDARD DEVIATION.

\begin{tabular}{|c|c|c|c|c|c|c|c|}
\hline \multirow[t]{2}{*}{ Task dimensions } & \multirow[t]{2}{*}{ condition } & \multicolumn{2}{|l|}{ Low level } & \multicolumn{2}{|c|}{ Average level } & \multicolumn{2}{|c|}{ High level } \\
\hline & & M & SD & M & SD & $\mathbf{M}^{\circ}$ & SD \\
\hline \multirow{2}{*}{ Planning time } & + & 3.16 & 1.085 & 3.27 & .800 & 3.33 & .786 \\
\hline & - & 3.33 & .907 & 4.09 & .927 & 4.12 & 1.044 \\
\hline \multirow{2}{*}{ Perspective } & + & 2.76 & .895 & 3.27 & .831 & 3.28 & 1.421 \\
\hline & - & 3.91 & 1.085 & 4.00 & 1.118 & 4.00 & .944 \\
\hline \multirow{2}{*}{ Prior knowledge } & + & 3.78 & .943 & 4.04 & 1.274 & 4.09 & 1.446 \\
\hline & - & 4.50 & 1.618 & 5.00 & 1.155 & 5.55 & 1.809 \\
\hline
\end{tabular}

As the Table 1 shows, In the planning time dimension, mean results showed better performance for high level (4.12) than average and low levels $(4.09,3.33)$ in - condition (having time to look at the listening items before listening to the tasks). In + condition (not having time to look at the listening items before listening to the tasks), the rank of students' listening scores was according to the students` proficiency levels high, average and low $(3.33,3.27$ and 3.16), that is the higher the proficiency, the higher the listening score.

Given perspective, mean results illustrated equal listening score for high and average levels (4.00) and for low ones (3.91) in - condition (listening to task with first person point of view). Although high proficiency students compared to low level ones outperformed on the test, high and average level score are the same. In + condition (listening to task with third person point of view), students' listening scores for high, average and low levels were 3.28, 3.27 and 2.76, respectively. This shows little difference between students' listening performance (esp. for average and high) with different proficiency levels.

Considering prior knowledge, Mean results indicated following listening scores for high, average, and low levels 4.09, 4.04 and 3.78, respectively under + condition (without prior knowledge). For - condition (with prior knowledge), results were for high, average, and low levels 5.55, 5.00 and 4.50, respectively. Like in + condition, in - condition the higher proficiency students outperformed on the tasks. Of course, students generally did better under simple condition than complex one.

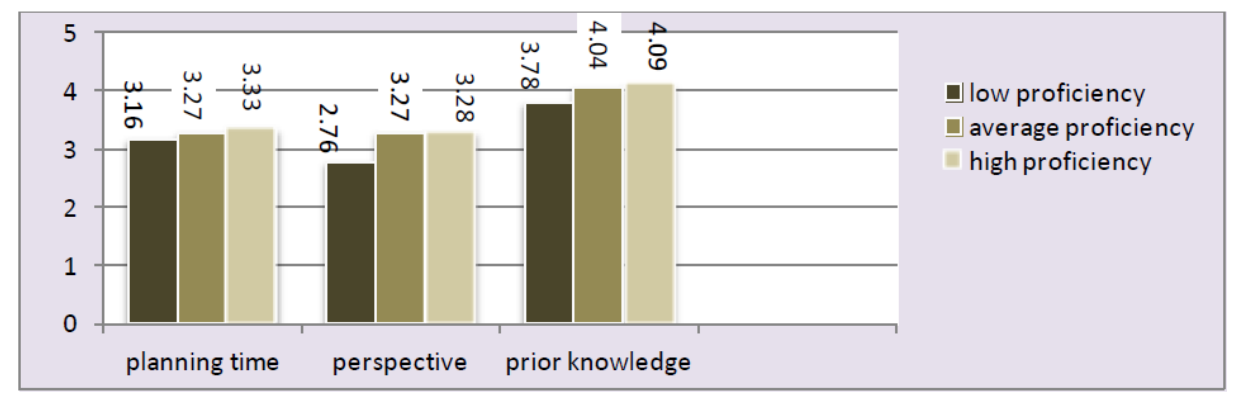

Figure 1. Students Comprehension for Three Level of Proficiency under Complex Condition

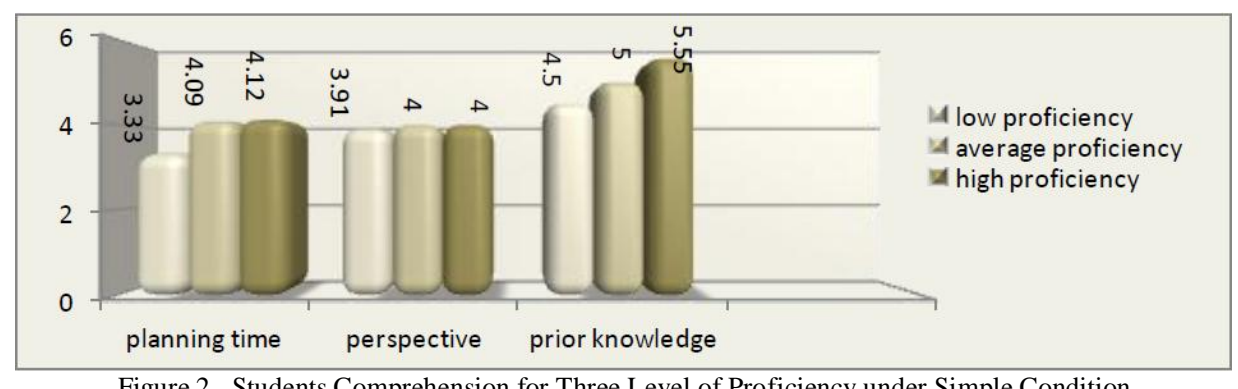

Figure 2. Students Comprehension for Three Level of Proficiency under Simple Condition

As Figure 1 demonstrates, high proficiency students outperformed on all three dimensions of planning time, perspective and prior knowledge under complex condition. Of course, none of these differences were significant. But as shown in Figures 1 and 2, students had better listening performance scores under simple condition than complex one for 
all proficiency (low, average and high). It can be observed that there are slight differences between students' comprehension and proficiency level for all three task dimensions under the two +/- performance conditions.

To see whether the mean differences reported above are significant and to test hypothesis 1 , One-Way Repeated Measures of ANOVA was performed (Table 2 and 3). As shown in Table 1, there is a significant difference among three proficiency levels only for -/simple planning time (having time to look at listening items), $F(2,51)=3.424$, $p=.040 *$ (See Table 2).

TABLE 2.

RESUltS OF THE TESTS OF BETWEEN-GROUP AND WITHIN-GROUP EFFECTS MEASURED By REPEATED MEASURES ANOVA FOR SIMPLE TASKS.

\begin{tabular}{|ll|l|l|l|l|l|}
\hline Dimensions & Sum of Squares & df & Mean Square & F & Sig \\
\hline Planning time & Between group & 6.483 & 2 & 3.241 & 3.424 &. $.040 *$ \\
& within group & 48.276 & 51 & .947 & & \\
& Total & 54.759 & 53 & & & \\
\hline Perspective & Between group & .652 & 2 & .326 & .307 & .737 \\
& within group & 54.182 & 51 & 1.062 & & \\
& Total & 54.833 & 53 & & .249 & .781 \\
Prior & Between group & .762 & 2 & .381 & & \\
Knowledge & within group & 78.071 & 51 & 1.531 & & \\
& Total & 78.833 & 53 & & & \\
\end{tabular}

TABLE 3.

RESUltS OF THE TESTS OF BETWEEN-GROUP AND WITHIN-GROUP EFFECTS MEASURED By REPEATED MEASURES ANOVA FOR COMPLEX TASKS.

\begin{tabular}{|ll|l|l|l|l|l|}
\hline Dimensions & & Sum of Squares & df & Mean Square & F & Sig \\
\hline Planning time & Between group & .599 & 2 & .300 & .351 & .706 \\
& within group & 43.549 & 51 & .854 & & \\
& Total & 44.148 & 53 & & & \\
\hline Perspective & Between group & 3.573 & 2.353 & 1.786 & 1.740 & .186 \\
& within group & 52.35 & 51 & 1.027 & & \\
& Total & 55.926 & 53 & & 1.045 & .359 \\
\hline Prior & Between group & 4.714 & 2 & 2.357 & & \\
Knowledge & within group & 114.990 & 51 & 2.255 & & \\
& Total & 119.704 & 53 & & & \\
\hline
\end{tabular}

In addition, a Tukey's LSD test on the pairwise comparisons revealed a significant difference between low and average proficiency level $(p<.05)$, as demonstrated in Table 4.8. This means that average proficiency group yielded better performance than low proficiency group.

TABLE 4.

Results OF THE Post Hoc LSD TEST ON PROFICIENCY LEVEL MEASURED By REPEATED MEASURES ANOVA

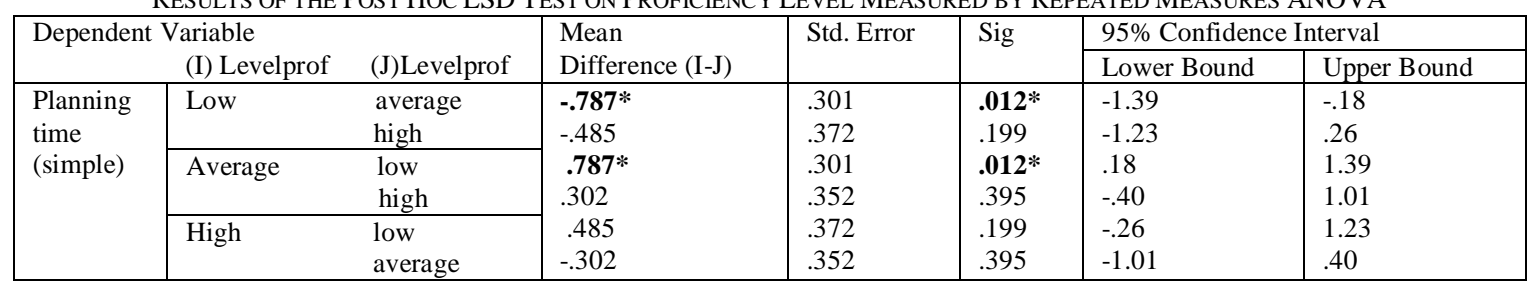

As an important point in relation between complexity and proficiency levels, this study wanted to indicate the effect of proficiency on task complexity. As we can see in the above tables, results illustrate that only significant difference $(p=.012)$ is between low and average just for simple condition. On the basis of these findings and $\mathrm{F}$ values found in analyses, our null hypothesis that predicted no difference between students' listening performance and proficiency was rejected only for immediacy under simple condition.

H2: There is no difference between learners' anxiety and students' task comprehension under different performance conditions.

To see the effect of anxiety on task complexity, the total scores of the student's task performance for three levels of anxiety (low, average, high) were analyzed using descriptive analysis of mean and standard deviation. Mean comparison was run between simple \& complex conditions. Results of descriptive statistic were presented in Table 5. 
TABLE 5.

DESCRIPTIVE STATISTICS OF STUDENTS' COMPREHENSION SCORES FOR THREE LEVELS OF ANXIETY (LOW, AVERAGE, AND HIGH) UNDER + / CONDITIONS.

\begin{tabular}{|c|c|c|c|c|c|c|c|}
\hline Task dimension & Condition & \multicolumn{2}{|c|}{ Low level } & \multicolumn{2}{|c|}{ Mid level } & \multicolumn{2}{|c|}{ High level } \\
\hline \multirow{3}{*}{ Planning time } & & $\mathrm{M}$ & SD & $\mathrm{M}$ & $\mathrm{SD}$ & $\mathrm{M}$ & SD \\
\hline & + & 3.23 & .951 & 3.20 & 1.304 & 3.13 & .815 \\
\hline & - & 3.60 & .894 & 2.83 & 1.029 & 2.62 & .983 \\
\hline \multirow[b]{2}{*}{ Perspective } & + & 3.20 & 1.095 & 3.13 & 1.140 & 2.92 & .935 \\
\hline & - & 3.96 & 1.022 & 3.96 & 1.076 & 3.80 & .837 \\
\hline \multirow[b]{2}{*}{ Prior knowledge } & + & 4.08 & 1.055 & 4.00 & 1.225 & 3.78 & 1.413 \\
\hline & - & 5.13 & 1.576 & 5.00 & 1.225 & 4.73 & 1.511 \\
\hline
\end{tabular}

In the planning time dimension, mean results showed better listening for low, average and high anxiety levels (3.60, 2.83, and 2.63) in - condition (i.e., having time to look at the listening items before listening to the tasks), respectively. For + condition (not having time to look at the listening items before listening to the tasks), this order was low, average and high anxiety levels $(3.23,3.20$, and 3.13), respectively. The results show that the lower the anxiety, the better performance on the task. Given perspective, mean results displayed better listening scores for low and average levels $(3.96,3.96)$ than for high $(3.80)$ level in - condition (i.e., answering after listening to task with first person point of view), that is the lower the anxiety, the higher the task performance. In + condition (i.e., answering after listening to task with third person point of view), students' listening scores in low level (3.20) were greater than high and average levels $(2.92,3.13)$. The results are according to the expected condition, i.e. the lower the anxiety, the better the performance. For prior knowledge, mean results showed highest listening scores respectively for low, average and high levels of anxiety $(5.13,5.00$ and 4.73) under - condition (i.e., listening to the task items with prior knowledge). For + condition (i.e., listening to the task items without reading prior knowledge), rank of listening scores are from low to high (4.08, 4.00 and 3.78), respectively.

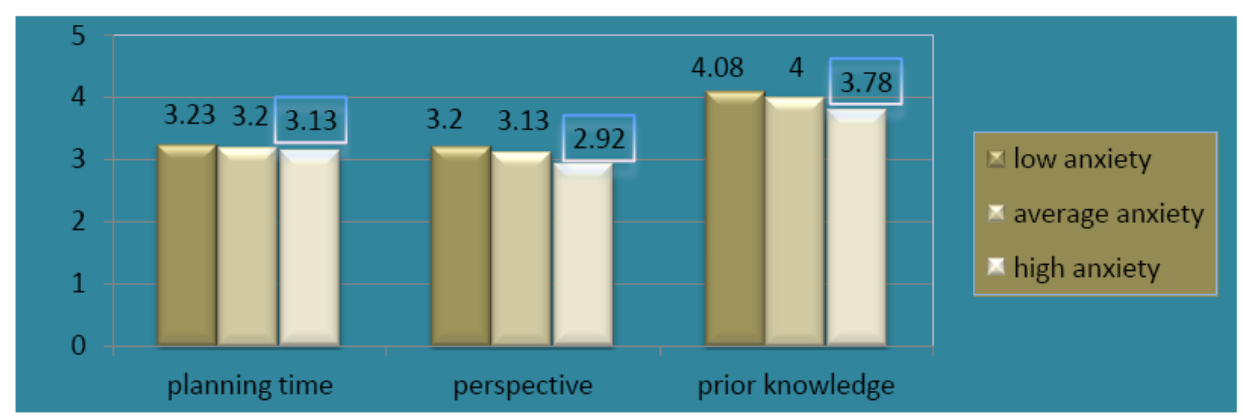

Figure 3. Mean of Students' Comprehension Scores for Three Level of Anxiety (Low, Average and High) under Complex Condition.

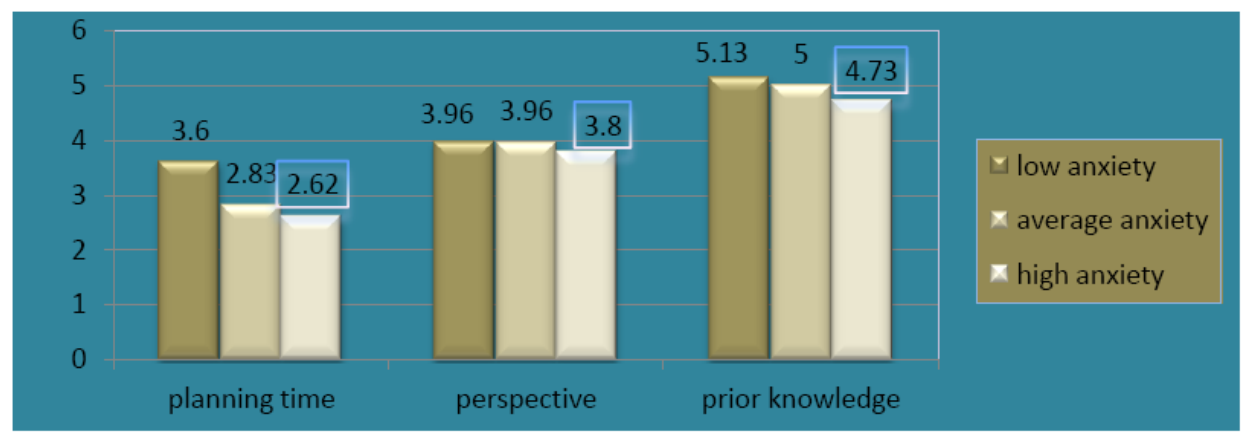

Figure 4. Mean of Students' Comprehension Scores for Three Level of Anxiety under Simple Condition

As Figures 3 and 4 demonstrate, there are slight differences between students' performance and level of anxiety for all task dimensions under the two (+/-) performance conditions. As shown in Figures 3 and 4, first, students outperformed under -/simple condition rather than complex /+ one and second, no remarkable differences were found for different levels of anxiety under different performance conditions.

To see whether the mean differences reported above are significant and to test hypothesis 2, One-Way Repeated Measures of ANOVA was run. Results, summarized in Table 6, showed that there are not any significant differences among the three anxiety levels under both simple and complex conditions. 
TABLE 6

RESUlts OF THE TESTS OF BETWEEN-GROUP AND WITHIN-GROUP EFFECTS MEASURED By REPEATED MEASURES ANOVA

\begin{tabular}{|c|c|c|c|c|c|c|}
\hline Dimensions & & $\begin{array}{l}\text { Sum of } \\
\text { Squares }\end{array}$ & $d f$ & $\begin{array}{l}\text { Mean } \\
\text { Square }\end{array}$ & $F$ & Sig \\
\hline Planning time (S) & $\begin{array}{l}\text { Between group } \\
\text { within group } \\
\text { Total }\end{array}$ & $\begin{array}{l}3.566 \\
51.193 \\
54.759 \\
\end{array}$ & $\begin{array}{l}2 \\
51 \\
53 \\
\end{array}$ & $\begin{array}{l}1.783 \\
1.004\end{array}$ & 1.776 & .180 \\
\hline perspective (S) & $\begin{array}{l}\text { Between group } \\
\text { within group } \\
\text { Total } \\
\end{array}$ & $\begin{array}{l}.181 \\
54.652 \\
54.833 \\
\end{array}$ & $\begin{array}{l}2 \\
51 \\
53 \\
\end{array}$ & $\begin{array}{l}.091 \\
1.072\end{array}$ & .085 & .919 \\
\hline $\begin{array}{l}\text { Prior } \\
\text { Knowledge (S) }\end{array}$ & $\begin{array}{l}\text { Between group } \\
\text { within group } \\
\text { Total }\end{array}$ & $\begin{array}{l}.941 \\
77.892 \\
78.833\end{array}$ & $\begin{array}{l}2 \\
51 \\
53\end{array}$ & $\begin{array}{l}.471 \\
1.527\end{array}$ & .308 & .736 \\
\hline Planning time $(\mathrm{C})$ & $\begin{array}{l}\text { Between group } \\
\text { within group } \\
\text { Total }\end{array}$ & $\begin{array}{l}.724 \\
43.425 \\
44.148\end{array}$ & $\begin{array}{l}2 \\
51 \\
53\end{array}$ & $\begin{array}{l}.362 \\
.851\end{array}$ & .425 & .656 \\
\hline Perspective (C) & $\begin{array}{l}\text { Between group } \\
\text { within group } \\
\text { Total } \\
\end{array}$ & $\begin{array}{l}.163 \\
55.763 \\
55.926 \\
\end{array}$ & $\begin{array}{l}2 \\
51 \\
53 \\
\end{array}$ & $\begin{array}{l}.081 \\
1.093\end{array}$ & .075 & .928 \\
\hline $\begin{array}{l}\text { Prior } \\
\text { Knowledge (C) }\end{array}$ & $\begin{array}{l}\text { Between group } \\
\text { within group } \\
\text { Total }\end{array}$ & $\begin{array}{l}.150 \\
119.554 \\
119.704\end{array}$ & $\begin{array}{l}2 \\
51 \\
53\end{array}$ & $\begin{array}{l}.075 \\
2.344\end{array}$ & .032 & .969 \\
\hline
\end{tabular}

As Table 6 illustrates, although there are no significant differences among all three anxiety groups, students tend to perform better on low level of anxiety. On the basis of $\mathrm{F}$ values found in analyses of all anxiety levels for, our null hypothesis that predicted no difference between students' listening performance and anxiety was confirmed for all task dimensions under simple and complex conditions.

\section{DisCUSSION AND CONCLUSION}

H1: There is no difference between test-takers' listening performance with different proficiency levels under simple and complex conditions.

There is some evidence, however, that prior knowledge may interact with proficiency level in facilitating task performance. Clapham (1996) found prior knowledge of a domain did not facilitate performance for subjects taking reading tests who were at a low level of proficiency, but increasingly facilitated performance for subjects at higher levels of proficiency. According to Wigglesworth (1997), all second language learners at all levels of proficiency have, to some degree, a choice about what they will say, and the structures that they will use to say it. As they become fluent and competent speakers of their second language, learners are ultimately moving towards automaticization, and the decisions they make about what they practice are crucial in determining their future language use since the planning period will to some degree determine what aspects of their interlanguage will and will not become automatized. Wigglesworth (1997) in "an investigation of planning time and proficiency level on oral test discourse" found that for high proficiency candidates, planning time may improve accuracy on some measures where the cognitive load of the task is high, but that this effect does not extend to the low proficiency candidates. In a study by Urwin (1995), he investigated the effects of prior knowledge on the lecture comprehension of adult second language learners of Chinese. Urwin's (1995) study results showed superior performance by the prior knowledge groups relative to the control group only on inference questions.

Operationalzing students' proficiency level by dividing them into three levels based on the proficiency test, testtaker's listening comprehension scores was compared with their proficiency levels (low, average and high) under two +/complex and - /simple conditions for each dimension. Considering the planning time, rank of proficiency level on students' listening score for both simple \& complex conditions were high, average and low, respectively. These rankings illustrate exact correspondence between proficiency level and students' performance for both simple \& complex conditions (i.e., the higher the proficiency, the better the performance).

Given perspective dimension, rank of proficiency level on students' listening score for $-\&+$ conditions were (high $=$ average) and low and high, average and low, respectively. Regarding the perspective, students with all three levels of proficiency had better listening performance on first person perspective (simple/-) than third person one (+/complex). The high proficiency students roughly had the same listening comprehension as the low proficiency ones under both simple and complex performance conditions. For prior knowledge, order of proficiency level on students' listening score for both $-\&+$ conditions were high, average and low. It can be concluded that high proficiency students outperform under both $-\&+$. Results showed that all three levels of proficiency had better listening comprehension on the presence of prior knowledge (-) than lack of prior knowledge (+). The high proficiency students had slightly better performance under complex condition.

H2: There is no difference between learners' anxiety and students' task comprehension under different performance conditions.

According to Tobias (1986), interference may occur at three levels: input, processing and output. At input, anxiety may cause attention deficits and poor initial processing of information. In short, not as much information is registered. 
For example, people with higher anxiety seem easily distracted from the task because time is divided between the processing of emotion-related and task-related cognition. If the task is relatively simple, anxiety may have little effect on processing. The more difficult the task, the greater the effect of anxiety on processing. Also Horwitz, Horwitz and Cope (1991) consider FLCA as "a distinct complex of self perceptions, beliefs, feelings, and behaviors related to classroom language learning arising from the uniqueness of the language learning process". In all of these specifications, the context or situation dependent nature of foreign language anxiety was emphasized

With regard to planning time dimension, rank of anxiety level on students' listening score for both -/simple \& $+/$ complex conditions were low, average and high, respectively. Total correspondence was found between anxiety level and students' performance under both $+\&$ - conditions. Results showed that under both $-\&+$ conditions students with low level of anxiety had better performance than those with high level of anxiety. This is in correspondence with the statement that the lower the anxiety levels, the higher the listening performance.

Given perspective dimension, rank of anxiety level on students' listening score for conditions -/simple $\&+/$ complex were low = average and high, and low, average, and high, respectively. These rankings proved that except equal score for low and average levels under simple condition, there is total correspondence between anxiety level and students performance for both $+\&$ - conditions. Results showed that all low, average and high anxiety levels had better listening performance on simple condition (first person perspective). Shortly, students with low level of anxiety did not better on complex task. For prior knowledge, rank of anxiety level on students' listening score for both $+\&$-conditions were low, average and high, respectively. These statistics revealed complete correspondence between anxiety level and students comprehension (the lower the anxiety, the higher the listening score) under both $+\&-$ conditions. Statistics showed that students with all three levels of anxiety had better listening comprehension on simple task (presence of prior knowledge). Of course, low level anxiety students had better comprehension than high level anxiety students on complex task.

\section{CONCLUSION}

To sum up, in this study focus was on what is the effect of task difficulty factors, proficiency and trait anxiety on task complexity conducted through different performance conditions, simple and complex. For example, do test-takers with high proficiency and low anxiety experience less complexity in their task performance or do these task complexities correlate more with manipulation of performance conditions or maybe with some other difficulty factors like proficiency and anxiety. It has shown that the conditions, under which tasks are completed, can have a marked effect on the resultant nature of comprehension. The study has confirmed the generally beneficial effects of different performance conditions on student's listening comprehension across task dimensions, here, prior knowledge, planning time, and perspective. For the first research question, little difference was found in the listening comprehension among the three proficiency levels but totally high level students had better comprehension under both -/simple \& + /complex conditions. High level students performed slightly better than other two levels but no significant difference was found among three different levels of proficiency under two simple and complex performance conditions. To conclude, it should be emphasized that our first hypothesis, there is no difference between test-takers' task comprehension with different proficiency levels under simple and complex conditions, is confirmed.

With regard to second research question, as far as the effect of test-takers' anxiety is concerned; students had better comprehension for simple tasks than complex ones for all three levels of anxiety. As demonstrated in results of study, there was a total correspondence between test-takers` level of anxiety and their task performance. Although there were slight differences between test-takers`anxiety level and task performance under different performance conditions, no significant differences were found among three different anxiety levels under both simple and complex conditions. It can be concluded that our second hypothesis, there is no difference between learners' anxiety and students' listening task performance under different performance conditions, is confirmed. From the findings of this study, it can be concluded that slight differences between performance of test-takers under simple and complex conditions were mostly of performance condition and not of proficiency and anxiety.

One of the limitations of the present study was factors affecting task performance such as motivation and anxiety that are hard or impossible to diagnose in advance of test task performance, and so are problematic as a basis for a priori prospective decisions about sequencing tasks. Undoubtedly, the full extent of variation in task listening comprehension cannot be reduced to any one factor or dimension of that factor alone. However, it was attempted to make a case for basing sequencing decisions in task-based approaches to syllabus design on distinctions between the cognitive demands of tasks which contribute to their relative complexity. Ellis (2003, p.20) maintains, "One of the goals of task based research is to establish what language and cognitive processes are likely to occur when input, conditions, and procedures are systematically varied." Therefore, influence of other kinds of input tasks needs to be examined in future research. In the meantime, the goal of designing valid and reliable tasks for assessing listening competencies will remain vague. Third, the role of task conditions needs to be explored further. More sophisticated methods may need to be found for future research. Lastly, more studies that examine the value of task complexity and task difficulty within listening comprehension contexts need to be conducted. The findings in this thesis may also contribute useful information to the area of task-based testing. In this sense, they can be a contribution to the need of 
conceptualizing comprehension and the processing conditions which influence it. The different conditions under which tasks are performed have shown to generate radically different results.

\section{REFERENCES}

[1] Bachman, L., \& Palmer, A. (1996). Language testing in practice: Oxford and New York: Oxford University Press.

[2] Brindley G., \& Slayter, H. (2002). Exploring task difficulty in ESL listening assessment. Department of Linguistics, School of English and Linguistics, Macquarie University, Sydney, NSW 2109, Australia.

[3] Brown, G., Anderson, A., Shillcock, R., \& Yule, G. (1984). Teaching talk: Strategies for production and assessment. Cambridge: Cambridge University Press.

[4] Brumfit, C. (1984). Communicative methodology in language teaching. Cambridge: Cambridge University Press.

[5] Bygate, M. (2001). Effects of task repetition on the structure and control of oral language. In M. Bygate et al. (Eds.), Researching pedagogic task: Second language learning, teaching, and testing (pp. 23-48). Harlow: Longman.

[6] Clapham, c. (1996). The Development of IELTS: A Study of the Effect of Background Knowledge on Reading Comprehension. Cambridge: Cambridge University Press.

[7] Crookes, G. (1986). Task classification: A cross-disciplinary review. Technical report\#4. Honolulu: Center for Second Language Classroom Research, Social Science Research Institute, University of Hawai'i at Manoa.

[8] Davies, A., Brown, A., Elder, C., Hill, K., Lumley, T. \& McNamara. (1999). Dictionary of language testing. Cambridge: Cambridge University Press.

[9] Ellis, R. (2003). Task-based language learning and teaching. Cambridge. Cambridge University Press.

[10] Endler, N. S. (1980). Person-situation interaction and anxiety. In I. L. Kutash exploring interactions in a componential framework. Applied Linguistics 22, 27-57.

[11] Eysenck, M. W. (1979). Anxiety, learning, and memory: A reconceptualization. Journal of Research in Personality, 13, 363385.

[12] Gardner, R. C., \& MacIntyre, P. D. (1992). A student's contributions to second language learning. Part I: Cognitive variables. Language Teaching, 25, 211-220.

[13] Gardner, R. C., \& MacIntyre, P. D. (1993). A student's contributions to second language learning. Part II: Affective variables. Language Teaching, 26, 1-11.

[14] Gilabert, R. (2004). Task complexity and L2 narrative oral production. Unpublished PhD dissertation, University of Barcelona, Spain.

[15] Givon, T. (1989). Mind, code and context: Essays in Pragmatics. Hillsdale, NJ: Lawrence Erlbaum.

[16] Horwitz, E.K., Horwitz, M.B., \& Cope, J.A. (1991). Foreign language classroom anxiety. In E. K. Horwitz \& D. J. Young (Eds.), Language anxiety: From theory and research to classroom implications (pp. 27-36). Englewood Cliffs, New Jersey: Prentice Hall.

[17] Iwashita, N. and Elder, C. (1997). Expert feedback? Assessing the role of test-taker reactions to a proficiency test for teachers of Japanese. Melbourne Papers in Language Testing 6, 53-67.

[18] McNamara, T., Iwashita, N., \& Elder, C. (2001). Can we predict task difficulty in an oral proficiency test? Exploring the potential of an information-processing approach to task design. Language Learning, 51(3), 401-436.

[19] Kleinmann, H. H. (1977). Avoidance behavior in adult second-language acquisition. Language learning, 27, 93-707.

[20] Long, M. H. (1985). A role for instruction in second language acquisition: Task based language teaching. In K. Hyltenstam \& M. Pienemann (Eds.), Modeling and assessing second language acquisition (pp. 77-79). Clevedon, England: Multilingual Matters.

[21] Long, M. H. (1989). Task, group, and task-based interactions. University of Hawaii Working papers in ESL, 8 (2), 1-26.

[22] MacIntyre, P. D., \& Gardner R. C. (1991a). Anxiety and second language learning. Language anxiety: From theory and research to classroom implications (pp. 41-54). Englewood Cliffs, New Jersey: prentice Hall.

[23] MacIntyre, P. D., \& Gardner, R.C. (1989). Anxiety in second language learning: toward a theoretical clarification. Language Learning 39, 251-275.

[24] Pica, T. (1994). Research on negotiation: what does it reveal about second language learning, conditions, processes and outcomes? Language Learning, 44, 493-527.

[25] Pica, T., Kanagy, R., \& Falodun, J. (1993). Choosing and using communication tasks for second language instruction. In G. Crookes \& S. Gass (Eds.), Tasks and language learning: Integrating theory and practice (pp. 9-34). Philadelphia: Multilingual Matters.

[26] Prabhu, N.S. (1987). Second language pedagogy. Oxford: Oxford University Press.

[27] Robinson, P. (2001). Task complexity, task difficulty, and task production: exploring interactions in a componential framework. Applied Linguistics 22, 27-57.

[28] Robinson, P. (2001a). Task complexity, task difficulty, and task production: Exploring interactions in a componential framework. Applied Linguistics, 22 (1), 27-57.

[29] Robinson, P. (2001b). Task complexity, cognitive resources, and syllabus design: A triadic framework for examining task influences on SLA. In P. Robinson (Ed.), Cognition and second language instruction (pp. 287-318). Cambridge: Cambridge University Press.

[30] Robinson, P. (2003a). The cognition hypothesis, task design, and adult task-based language learning. Second Language Studies, 21 (2), 45-105.

[31] Robinson, P. (1995). Task complexity and second language narrative discourse. Language Learning 45: 99-140.

[32] Sarason, I. G. (1986). Test anxiety, worry, and cognitive interference. In R.Schwarzer (Ed.), Self-related acquisition in anxiety and motivation. Hillsdale, New Jersey: Lawrence Erlbaum Associates.

[33] Skehan, P. \& Foster, P. (2001). Cognition and tasks. In Robinson, P. (Ed.) Cognition and second language instruction. (pp. 183-205) Cambridge: Cambridge University Press. 
[34] Skehan, P. (1996). A framework for the implementation of task-based instruction. Oxford: Oxford University Press.

[35] Skehan, P. (1998). A cognitive approach to language learning. Oxford: Oxford University Press.

[36] Slatyer, H., Brindley, G., \&Wigglesworth, G. (2000). Task difficulty in ESL listening assessment. Paper presented at the 22nd Language Testing Research Colloquium, Vancouver, British Columbia, Canada.

[37] Spielberger, C. D. (1983). Manual for the state-trait anxiety inventory (form Y). Palo Alto, California: Consulting Psychologists Press.

[38] Sridhar, S.N. (1988).Cognition and sentence production: A cross-linguistic study. New York: Springer -Verlag.

[39] Taylor, J. A (f953). A personality scale of manifest anxiety. Journal of Abnormal and Social Psychology, 48,285-290.

[40] Tobias, S. (1986). Anxiety and cognitive processing of instruction. In R. Schwarzer (Ed.), Self-related cognition in anxiety and motivation. Hillsdale New Jersey: Lawrence Erlbaum Associates.

[41] Urwin, J. (1995). Prior knowledge pretasks and second language listening comprehension. Unpublished paper, University of Queensland, Australia.

[42] Widdowson, H. G. (1972). The teaching of English as communication. English Language Teaching and Learning 27 (1), 15-19: Integrating theory and practice. Clevedon, Avon: Multilingual Matters.

[43] Wigglesworth, G. (1997). An investigation of planning time and proficiency level on oral test discourse. Language Testing, 14, 85-106.

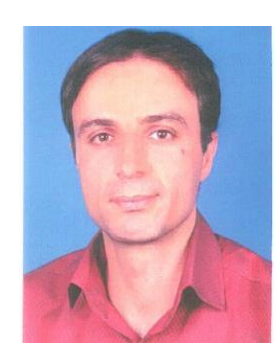

Mehdi Sadeghi Ghahdarijani was born in Isfahan; 1979. He was graduated in English literature from Tabriz University in 2004. Again he was accepted for MA in English Language Teaching in 2006 and graduated in 2008 from Kashan University. He has been teaching English for ten years from 2001 to 2011in some English teaching institutes in Iran. His areas of interest in English language teaching were vocabulary, task difficulty, task complexity and especially effect of anxiety on students' learning. 